July 26, 2004

\title{
On Thugs and Heroes: Why Warlords Victimize Their Own Civilians?
}

\author{
by Jean-Paul Azam \\ University of Toulouse (ARQADE and IDEI) \\ and Institut Universitaire de France.
}

\begin{abstract}
Violence against civilians is the mainstay of modern warfare, and claims $84 \%$ of the war-related casualties. Looting and terror are the two main reasons why the soldiers victimize the civilians from the other side. However, examples have been found (Congo, Sierra Leone,...) where the guerilla and the incumbent army abuse the civilians from their own side. The present paper offers a potential explanation for this phenomenon, based on strategic looting. It argues that this behavior helps drawing a line between thugs and legitimate rebels.
\end{abstract}

Acknowledgement: This paper is part of the PAC Project CIT-2-CT-2004-506084 funded by the European Commission. It has been presented at the "Rationalist Approaches to War and Conflict" Workshop at WZB in Berlin on July 17, 2004. Helpful comments by the participants, and in particular by the discussant Karl Wärneryd, as well as by Irwin Collier, David Dejong, Michelle Garfinkel, Anke Hoeffler, Karl Moene, James Morrow, Robert Powell and Gerald Schneider, are gratefully acknowledged, without implicating. 


\section{Introduction}

Although the idea of regimented war, as codified by Clausewitz, is still widely present in most people's mind, it is largely misleading nowadays. The case of two armies facing each other in a well-defined area, and shooting at each other without involving much collateral damage, is an image of the past. Journalists often describe as "battles" episodes of war where the guerilla or the government's army are simply inflicting a lot of damage to civilians, either by shelling and bombing towns or villages, or while soldiers are simply killing villagers with guns or machetes. Picasso's "Guernica" painting marks a watershed, symbolizing the horror of the layman faced with this new type of warfare, as the Nazis bombed the Spanish city, which supported the republican side, with a view to kill a lot of civilians. Civilians have become the main targets of violence in times of warfare. A widely cited figure estimates at $84 \%$ the fraction of civilians in war-related deaths (Cairns, 1997).

Azam (2002) and Azam and Hoeffler (2002) have analyzed this phenomenon of violence against civilians both theoretically and empirically. The former paper explores theoretically the impact of looting, assuming that the civilian casualties are the collateral damage of such activity, and the difference that it makes within a conflict-theoretic framework. The main results are first that violence against civilians by either side are strategic complements: when one side is the victim of some looting, this reduces the opportunity cost of labor, by deterring production, and thus provides an incentive for joining the army, and looting the other side. There is thus a multiplier effect regarding the number of soldiers allocated to looting. Second, in that model, looting is used as a substitute for missing funds, allowing to pay the soldiers, in a world of imperfect capital market. In Azam and Hoeffler (2002), the opposite effect is created by assuming that raiding civilians is not a collateral damage of looting, but is targeted instead at a military goal, namely to terrorize the peasants, and inducing them to flee the country. The aim is then to clear the ground from its population, in order to reduce the potential support that the guerilla or the army could find in its midst. Then a higher level of funding provides the means for performing more raiding. 
An empirical test of this prediction is presented, using the number of refugees from each country at war as a proxy for the incidence of violence against civilians in that country.

However, one observes also in the real world another type of violence against civilians, that these models do not capture. The experience of Sierra Leone (Abdullah and Muana, 1998), for example, or those of the Congoes, both Brazzaville and Kinshasa, show that soldiers often abuse the civilians from their own side, and not only those belonging to the opposing side. This has also been observed in several wars of de-colonization, in Algeria or Southern Rhodesia, for example. In these instances, the "liberation army" was inflicting a lot of violence to the peasants, ranging from torture to outright massacre, killing more people there than in the colonists' side.

A similar phenomenon has been observed, on a massive scale, during the recent Algerian civil war. The years 1997 and 1998 have witnessed the massacre of several thousand civilians in the central and the western parts of the country, including Algiers and its hinterland, where the FIS and the GIA insurgencies were deeply rooted. The Islamic party was running largely ahead of the incumbent party in these areas, when the 1992 elections were interrupted, what triggered the civil war. In contrast, Kabylia and the eastern part of the country, where these groups where less present, went through that period with very little violence. In these areas, only $2.96 \%$ and $6.43 \%$ of the civilian deaths occurred, in 1997 and 1998 respectively, out of a total of 7,478 and 4,498, respectively, for the whole country (Benouaret, 2004). The slaughtered villagers were much closer to the insurgents, both by the Arab language and the Islamic religion, than the Berber-speaking Kabyles. The latter were probably more wary of the insurgency at the outset than the Arab-speaking villagers in the west and the center, as they created self-defense groups, very early on during the war, in the villages and small towns of the Kabyle country. The villagers from the west and the center were much less suspicious, and created self-defense groups only later on in the course of the war. However, it seems implausible that this difference in self-protection could explain on its own the different incidence of civilian deaths cited above. It would also require some stretched credulity to believe that all these nearly 12,000 villagers, killed in 1997 and 1998, were all collaborating secretly with the ruling army, and were thus just punished for treason. 
Most of them were certainly innocent of any such conduct, and were thus massacred for other reasons. The present paper is an attempt at uncovering one of these potential reasons.

These types of violence against civilians, like the other two types described above, are conspicuously absent from the standard economics literature on conflict. The classic papers by Grossman (1991) and Hirshleifer (1991) are focusing on fighting proper. This is also true of most of the subsequent literature, which has stemmed from these two classics. In most of these models, the conflict technology is the focus of the analysis, which emphasizes the impact of some key parameters on the characteristics of the resulting equilibrium. In the model presented here, a similar type of conflict technology is assumed, but it does not play the same role. Here, the focus is centered on the collateral effects of the looting performed by the soldiers, and the conflict technology is only affecting the outcome through its incentive effects on the warlord's decision.

In Azam (2002), war is perceived to a large extent as a reciprocal tax tournament, where each side is seeking to grab some loot from the other side, for paying the soldiers' wages. By contrast, the warlords are assumed to collect taxes from their own folks in an orderly fashion, without any incentive effects. The government and the rebellion are treated symmetrically, so that either side is led by a warlord. Similarly, Olsson and Congdon Fors (2004) present a theoretical model of a war between two kleptocratic sides, with an application to the war in Congo-Zaïre since 1996. In the model presented below, a closer look is given at the way in which a warlord is managing his manpower for collecting "taxes" on his own side. It turns out that the warlord may have an incentive to go beyond simply collecting the loot, as a tax revenue, and to push strategically instead the level of looting further, in order to affect the labor market's equilibrium wage. The warlord is in fact in the position of a dominant employer, as in Azam's analysis of the Moroccan labor market (Azam, 1992). Although farming gives rise to a competitive fringe on the labor market, the warlord is in a position to exert some monopsony power. Then, raiding the farmers is liable to reduce the soldiers reservation wage. As in Azam (2002), there is no point in distinguishing between the government and the insurgency, as both sides behave as warlords. 
Hence, an important difference with Azam (2002) is that here the warlord does not exert full control over his own folks. There is a participation constraint, because unwilling soldiers can always desert in African or other armies of the third world, or simply avoid drafting by hiding in the bush, and go back to their fields, unless a proper incentive structure is provided. A similar constraint is assumed in Azam (2002), but it only plays a secondary role in that model. Here, it is at the center of the stage, and conditions are presented under which the warlord will use this constraint strategically. Herbst (2000) describes how insurgents sometimes use non economic incentives to impose loyalty on their recruits, thus reducing their reservation wage, in a way that is somehow related to the ones analyzed here. There is no need to go into these refined descriptions for the purpose of the present exercise. Another difference with Azam (2002) is that the analysis performed here uses a partial equilibrium framework, which is sufficient for bringing out the main point, while a general equilibrium setting is used there.

The crucial assumption involved in reaching this result has an important interpretation, which is bearing on some prominent issues of the dominant conflict literature. For example, the World Bank has recently published a major synthesis report on the theory and empirics of civil war, which presents some highly influential arguments (World Bank, 2003). Without going thoroughly into the details of the argument, for the sake of brevity, it is fair to say that this report assumes systematically that insurgents are to blame for the war, and can be regarded for all practical purposes, as criminals. Two issues are thus involved. First, there is the question of who is responsible for the outbreak of civil war. A good case can be made that this is always the government's choice, ultimately, as in the "social contract" theoretical framework developed by Azam and Mesnard (2003). Second, this implies a moral condemnation of the rebels. This point of view is reflecting a widely shared perception, which is somehow influenced by the legitimate condemnation of civil war by most observers. Most people find quite naturally that the widespread violence against civilians is morally unacceptable. As Edmund Cairns, an official from the world-wide NGO Oxfam, puts it: "Modern conflict [ ... ] challenges the very distinction between war and peace. It takes place typically not between armies, or even between the army of a state and its 
armed opposition in some easily-defined guerilla movement. The forces of both government and opposition, from Cambodia to Colombia, blend into illicit business and organized crime" (Cairns, 1997, p.5). In fact, Collier (2000) has coined the expression "quasi-criminal" activity for describing almost every type of rebellion. Similarly, an implicit moral condemnation is also present in the title of the highly influential "Greed and Grievance" paper by Collier and Hoeffler (2004).

However, in many historical cases, regarding the government as the "good side", and the rebels as the "bad guys", does not seem to provide an accurate picture of the relative legitimacy of the two sides, from the point of view of human rights, or that of the people's right to self-determination. While Mueller (2003) pays lip service to the fact that some rebels are "true believers", he argues that most of them can be regarded as "thugs", and should be treated accordingly. His paper does not offer a clear criterion for picking the good guys among rebels, while the need for such a cutoff line is dramatically felt. How would Che Guevara have become such a worldwide myth, still treated as a hero in popular songs, if all rebellion leaders were just thugs? A recent successful song talks about: “... tu querida presencia, Commandante Che Guevara". As a further example, it is perfectly clear that the backing that Ahmed Masood and the Northern Alliance were getting from the West in their fight against the Talibans in Afghanistan was not a simple tactical alliance. There was a deeply rooted view in the West that this was the "right side", against the forces of darkness epitomized by the Talibans (see e.g. Lévy, 2001). Masood was widely regarded as a hero. Both Masood and Guevara died young, which enhances the strength of the legend, but Foday Sankoh, the Sierra Leonian warlord, did not live very old either, without becoming a hero by any standards (Abdullah and Muana, 1998, Reno, 1998).

Another example of an insurgency which cannot be confused with a gang of thugs is the EPLF (Eritrean People's Liberation Front), according to Pool's analysis (Pool, 1998). The latter shows that this movement had a very clear political agenda, and was going out of its way in order to gain popular support in the liberated areas by engaging in various forms of social spending, in particular in the field of education and health. Comparing this type of behavior to the one consistently applied by the Derg government, on the other side of this 
conflict (Africa Watch, 1991), should definitely dispel the idea that insurgents are necessarily the bad guys, and that governments are legitimate all over the world, and deserve the support of the international community. A similar behavior is described by Young (1998) in his analysis of the TPLF (Tigray People's Liberation Front). The latter managed to convince the landed nobility to implement a land reform, which turned the peasants into active supporters, and improved significantly their fate. In 1978, the TPLF established the Relief Society of Tigray (REST), "a humanitarian organization with a mandate to coordinate relief programs, rehabilitation and development" (Young, 1998). By contrast, the behavior of the Ugandan government under Milton Obote or Idi Amin was clearly that of warlords using state power as a tool for pursuing their private agenda (Mutibwa, 1992). Therefore, the model presented below does not assume that all insurgents are "thugs", and it aims instead at capturing the significant difference that most analysts want to draw between thugs and legitimate warlords, be they rebels or incumbent governments.

This model explores the idea that legitimate warlords would treat their own side better than thugs would, and provides some microeconomic foundations for such a behavior. This viewpoint embeds the hypothesis that "legitimacy", for a rebel movement or a government, refers to the cause being defended, and the means chosen to defend it. The microeconomic foundations presented here allow to derive the latter from the former. The two polar cases are the pure criminal insurgency and the perfectly legitimate rebellion. The latter is done on behalf of a well-defined ethnic, religious, or national group, whose welfare can be improved by waging the war, compared to some status quo. In the former case, the rebel leader is viewed simply as an criminal entrepreneur, aiming at making illegal profit by plundering the country. Often, natural resources are playing a central role in this case. In the latter one, the rebel leader is described here as a kind of mythical "benevolent dictator", that standard public economics theory has taken from the enlightenment philosophers, as an ideal type (Gay, 1966). This perfectly legitimate insurgency seeks to maximize the standard utilitarian welfare criterion, while restricting the inclusion of individuals' utility functions in this social objective function to the members of a pre-defined group. Of course, whether the utilitarian welfare criterion is perfectly acceptable from an ethical point of view is a debated 
issue, which would take us too far afield (see Little, 2002, for a recent discussion of this point). In fact, the same type of distinction is also relevant for governments, in many developing countries. Many rulers in poor countries can be dubbed "thugs" by this criterion. It is hard to believe, for example, that Charles Taylor, when he was in power, or Mobutu Sese Seko, could legitimately be regarded as "heroes", by any objective standards (see e.g. Olsson and Congdon Fors, 2004, on Mobutu).

This distinction between thugs and heroes of course depends on the viewpoint adopted to look at it. Like the "social bandits" analyzed by Hobsbaum (2000), the legitimate rebels described here are viewed as "heroes" by one side, and as "thugs" by the other side. The paper offers an objective criterion for drawing a line between the two types, assuming at the outset that there is potentially a continuum of types between thuggery and legitimacy. This begs the question of erroneous perception. Thugs can pretend to be heroes, and they usually do so, at least for a while. One can trace the origin of ideology to such a deception strategy, whereby leaders reduce the reservation price of their followers by manipulating their beliefs (see Gay, 1966). However, the explicit treatment of asymmetric information is left for further research, and full information is assumed instead below. Here, the cutoff line between thugs and heroes is based on an observable type of action, namely the infliction by the warlord of violence on the civilians from his own side. The labels "thug" and "hero" are thus not simply assigned to the warlords using the analyst's superior knowledge of the relevant parameters, but could be assigned by the farmers themselves, on the basis of the warlord's observable behavior.

The model presented below thus offers some microeconomic foundations for the behavior just described, and shows that the line to be drawn between thugs and heroes does not depend exclusively on the warlord's characteristics, like the parameter capturing the relative weight that he gives to his people's welfare in his objective function. Thus, it cannot be regarded as a purely moral issue, as the use of the value-laden word "thug" could misleadingly suggest. It depends also on the conflict technology. Hence, the latter is coming back at the front stage, but in a different role compared to the one brought out by the classic papers cited above. It interacts with the more ethical characteristics of the warlord's objective 
function, i.e. his degree of altruism towards his own group, for determining how much violence will fall on the civilians. This paper thus provides some potential foundations for the diagnosis put forward by Mueller (2003) that there are more thugs among rebels nowadays than in the past. This would be the result in the present model of a more decisive conflict technology, providing nowadays an incentive to hire more soldiers, and thus to manipulate the labor market with a view to depress their wages further down. Estimating empirically whether this is actually true in real-world civil wars falls outside the scope of the present paper. One implication of this result, that the warlord's ethical characteristics interact with the state of the conflict technology for determining the choice of using this type of violence, is that conflict scientists should switch to the use of a more neutral vocabulary. They should reject the moral overtones attached to such words as "thugs", "criminals", or even "greed". Using a more dispassionate terminology would thus avoid the risk of blaming automatically the war on the rebels.

Section 2 below describes the simple setting of the model, while the subsequent one is devoted to the derivation of the thugs versus heroes taxonomy, drawing a cut off line in the parameter space. Section 4 introduces another potential determinant, namely humanitarian relief. It shows that relief operations, by shielding the soldiers' reservation wage from the effect of raiding on farmers, reduces the warlord's incentive to adopt a thuggish behavior. This is the main policy-oriented result of this paper. Section 5 concludes.

\section{The Model}

The main point of this analysis can be derived within a partial equilibrium framework, which models the behavior of one warlord towards his own people, taking as given the other side's behavior. This is sufficient for bringing out the main parameters that determine which warlord is going to behave as a thug, and which one as a hero. The crucial action that is taken as the hallmark of thugs is the perpetration of violence against civilians from their own side. For the sake of contrast, we call the other ones "heroes", although this contains admittedly an element of abuse of language. 
Assume that there is a large number $N$ of identical individuals from whom the warlord is liable to recruit soldiers, and on behalf of whom he is waging the war. A natural interpretation is that $N$ measures the number of valid men in the warlord's ethnic group. This can of course be extended to the case of a group defined along religious lines, or to a coalition of groups. Each of these individuals can work as a farmer, for producing 1 unit of output. As the behavior of the enemy forces is not modeled explicitly here, this output may be interpreted as measured net of the looting performed by the other side's soldiers. However, each farmer is not certain to enjoy the benefit of this production, as he might be raided with probability $q$ by soldiers from his own side, who will grab $0<\delta \leq 1$ units of output away. There are $0<L \leq N$ farmers, while the remaining individuals are employed as soldiers by the warlord. The latter allocates his forces between two types of activity, with $F$ soldiers being engaged in fighting, while $R$ soldiers are employed for looting the farmers. The aim of the present exercise is to bring out the conditions under which $R>0$. Assuming that all the raiders are identical, and that all the farmers are also identical, it is natural to assume that:

$$
q=R / L, \text { if } R \leq L,
$$

and

$$
q=1, \text { if } R \geq L .
$$

The former case is more relevant for the real world, and is the focus of the analysis presented below.

Now, while the warlord is assumed to control perfectly his soldiers, as far as their allocation between fighting and raiding civilians is concerned, he cannot determine unilaterally the total number of such soldiers without fulfilling their participation constraint. The warlord can only decide on the allocation of his people between farming and soldiering if the individuals have no incentive to favor one activity over the other. For the sake of simplicity, no subjective or objective resource cost is assumed, either in fighting or in farming. Participation is thus decided by considering the opportunity cost of joining the army, taking only into account the material reward of each activity. It would be very easy to 
add a constant subjective cost of soldiering, for example, without changing substantively the analysis. Similarly, risk aversion is ruled out, for the sake of simplicity. Denote $w$ the wage rate earned in soldiering. Then, the individual will be indifferent between farming and soldiering if:

$$
w=1-\delta q
$$

This equation (3) lies at the heart of the strategic looting that the warlord can perform. It entails that a higher probability of raiding each farmer $q$ is liable to depress their reservation wage for joining the army, and thus to reduce the wage cost of the soldiers $w$.

Whilst this constraint holds, the warlord chooses both $F$ and $R$ (and thus $L$ ) subject to the full employment constraint:

$$
L+F+R=N
$$

The welfare of the warlord's people is described by the simple utilitarian criterion, which sums their utility functions over all the relevant individuals, keeping the warlord's own welfare out. Here, the simplest setting is assumed, describing the utility level reached by each individual by his consumption level, measured in units of output. Hence, a soldier gets a utility level $w$, while a farmer gets an expected utility level $1-\delta q$. It follows that the warlord's people total welfare is given by:

$$
W=(1-\delta q) L+w(N-L)
$$

Taking into account the participation constraint (3) yields immediately:

$$
W=w N
$$

The warlord is waging the war with a view to grab for himself a given prize, whose value is normalized to 1 , with a probability $p(F)\left(p^{\prime}(F)>0, p^{\prime}(0)>1, p^{\prime \prime}(F)<0\right)$. Moreover, he collects all the loot captured by the raiders, which he redistributes in part as wages to the soldiers, and uses also for his own consumption. 
Therefore, the warlord's profit may be written as:

$$
\pi=p(F)+\delta R-w(F+R)
$$

While a thug will be mainly interested in profiteering from the war, the model allows potentially for a more altruistic behavior on the part of the warlord, with a view to capture the difference between thugs and heroes described in the introduction. Denote $0 \leq \alpha \leq 1$ the warlord's degree of altruism towards his own people. The perfect thug corresponds without doubt to the case where $\alpha=0$, while the genuine utilitarian warlord would treat his own welfare on a par with that of any other of his group's member, with $\alpha=1$. Any value of $\alpha$ within the $[0,1]$ interval is allowed in this model, for capturing all possible intermediate cases. Then, he is assumed to choose $F, R$ and $w$ with a view to maximize:

$$
V=\pi+\alpha W
$$

It is in fact convenient to define also the warlord's self-interest premium as $\theta=1-\alpha, 0 \leq \theta \leq 1$. This is a natural measure of the warlord's degree of self-interest. Hence, this simple framework allows to describe the two extreme cases of the pure thug, who is only interested in his own profit $(\theta=1)$ and the case of the perfect utilitarian leader, who regards himself as just one among his own group's members $(\theta=0)$. It can also describe all the intermediate cases, where $\theta$ can take a continuum of values between these two extremes. The standard utilitarian objective function used in public economics theory would assume $\theta=0$. As shown below, knowledge of this parameter is not enough to determine who will behave like a thug, and who will be a hero. The latter label is reserved to the case where the warlord chooses $R=0$, while all the other warlords are regarded as thugs.

Substituting from (5) and (6) into (8), using (4), allows to write the warlord's objective function in the following way:

$$
p(F)+\delta R+\alpha w L-\theta w(F+R)
$$


This expression brings out one the core issues that determines the distinction between the thug and the hero. The first three terms in the sum can be regarded as the revenue side of this extended profit function, while the fourth term is clearly the labor cost of maintaining the army. The standard wage cost $w(F+R)$ is weighted here by a coefficient $\theta$ which is liable to yield a completely different interpretation of this wage cost for the thug and for the hero. Taking the two extreme cases brings out this point very clearly. For the perfect thug $(\theta=1)$ the wage cost is entered in the standard fashion, with a coefficient equal to 1 . However, for the perfect hero $(\theta=0)$, the resulting coefficient is 0 , so that the wage cost disappears from this extended profit function. The intuition for this result is that the perfect hero does not regard the wages paid as a labor cost, but as a transfer in favor of his people. Hence, this enters positively his altruistic objective function, offsetting the negative effect of the wage cost in the profit function. In the following, we are not particularly interested in these two extreme cases, and we focus instead on the intermediate cases, where the knowledge of $\theta$ is not sufficient for predicting who will behave as a thug, and who will behave as a hero. Nevertheless, the correct intuition can be constructed from these two extreme cases by continuity.

Define $\lambda=L / N$ as the share of the farmers remaining among the warlord's people, after the soldiers have been drafted. This also measures output per capita for the group under study. Then, another useful way of expressing the warlord's objective function is as follows:

$$
\pi+\alpha W=p(F)+\delta R+(\lambda-\theta) w N
$$

The coefficient $\lambda-\theta$ thus measures the net impact on the warlord's extended profit of an increase in the welfare of his people. The perfect utilitarian $(\theta=0)$ would thus simply maximize output, as $\delta R+\lambda w N=L$, i.e. agricultural output. However, the more selfinterested warlord $(\theta>0)$ will discount agricultural output to some extent, because it implies "leakages", as some of it only affects his welfare through his people's consumption $w N$. This concerns that part of agricultural output that does not enter directly his utility function, namely $(L-\delta R)$. 


\section{Sorting Out Thugs and Heroes}

The possibility of raiding the farmers for depressing wages introduces a nonconvexity in the model, and precludes a standard marginal analysis. Intuitively, this is due to the fact that when raiding is profitable, it entails some increasing returns to scale: raiding more reduces the wage cost of the soldiers, providing an incentive to perform yet more raiding. On the other hand, when raiding is not profitable, reducing it provides an incentive for reducing it still further, by raising the wage cost.

This comes out clearly by substituting (1), (3), (4), (6) and (7) into (8), for writing the latter as:

$$
V=p(F)+\frac{N-F}{1+q}-\theta(1-\delta q) N
$$

Differentiating (11) twice with respect to $q$ yields:

$$
\frac{\partial^{2} V}{\partial q^{2}}=\frac{2(N-F)}{(1+q)^{3}} \geq 0 .
$$

Therefore, the warlord's objective function $V$ is in fact convex, precluding the use of the standard methods of concave programming. As a result, only the extreme values of $q=0$ or $q=1$ can be observed in equilibrium. The aim of the present section is to find out the conditions under which the former or the latter prevails in equilibrium. It will be convenient to use the following definitions.

Definitions 1: (i) A hero equilibrium is a local optimum that maximizes (11) with $q=0$;

(ii) a thug equilibrium is a local optimum that maximizes (11) with $q=1$.

The conditions under which a hero equilibrium or a thug equilibrium exists are first identified, before analyzing the further conditions under which either equilibrium type is the warlord's global optimum. This is the topic of the two lemmas presented below. Before coming to that, we need to introduce a bit more notation. 
As announced in the introductory section, the thug/hero taxonomy derived from the present model depends both on the warlord's degree of self-interest, and on the properties of the conflict technology. The key point about the latter can be captured as follows. Define the decisiveness factor as $F(0)=p^{\prime-1}(1)$ and define as $f(0)=F(0) / N$ its per capita value. The latter is a convenient way of characterizing the conflict technology, for a given population size. It is less than 1 as soon as some farmers remain active, as assumed in what follows. It is related to Hirshleifer's decisiveness parameter (Hirshleifer, 1995), which is used for measuring the impact of an increase in the relative forces engaged in the fighting by one side on the probability of wining. The steeper the slope of this probability function, the more decisive can an increase in the relative level of the forces engaged be. Then, what matters is to measure somehow the shift of the $p^{\prime}(F)$ function, which is located higher, given $F$, the more decisive is the conflict technology. The decisiveness factor defined above $F(0)$ helps to measure such a shift in the neighborhood of $p^{\prime}(F)=1$, taken as a benchmark. The decisiveness factor $F(0)$ defined above is an increasing function of the position of the $p^{\prime}(F)$ function in the relevant space.

Lemma 1: A hero equilibrium exists if:

$$
\theta \leq \frac{1-f(0)}{\delta}
$$

Proof: If $q=0$, the warlord's extended profit function may be written as:

$$
V(0)=\max _{F} p(F)-F+(1-\theta) N
$$

The first-order condition for this problem yields $p^{\prime}(F)=1$, so that the equilibrium values of the endogenous variables are:

$$
\begin{aligned}
& F=F(0), \\
& L(0)=N-F(0),
\end{aligned}
$$

and:

$$
w(0)=1 \text {. }
$$


For this to be a local optimum, we require in addition that:

$$
\frac{\partial V(0)}{\partial q}=F(0)-(1-\theta \delta) N \leq 0
$$

This occurs if condition (13) holds. QED

Lemma 2: A thug equilibrium exists if:

$$
\theta \geq \frac{1-f(1)}{4 \delta}
$$

where $f(1)>f(0)$ is defined by $f(1)=F(1) / N$ and $p^{\prime}(F(1))=1 / 2$.

Proof: When $q=1$, the warlord's objective function can be written as:

$$
V(1)=\max _{F} p(F)-\frac{F}{2}+\left(\frac{1}{2}-\theta(1-\delta)\right) N
$$

Then, the first-order condition is $p^{\prime}(F)=1 / 2$, so that the equilibrium values of the endogenous variables are:

$$
\begin{aligned}
& F=F(1)>F(0), \\
& L(1)=\frac{N-F(1)}{2},
\end{aligned}
$$

and:

$$
w(1)=1-\delta
$$

For this to be a local optimum, we require in addition that:

$$
\frac{\partial V(1)}{\partial q}=N\left(\theta \delta-\frac{1-f(1)}{4}\right) \geq 0
$$

this occurs if condition (19) holds. QED

Notice that the lower bound given by (19) is always located below the upper bound given by (13), so that there exists a range of parameter values for which both type of local 
optima exist. Moreover, the thug equilibrium is characterized by a lower wage rate, and a larger number of fighters being employed than in the hero equilibrium. As a result, the number of farmers left, and thus the level of output are much lower in the thug equilibrium than in the hero equilibrium. The properties of the thug equilibrium show that raiders and fighters are complementary beyond a point, as $F(1)>F(0)$ and $R(1)=L(1)>0$. This illustrates the strategic role played by the raiding of civilians, which allows the warlord to increase the size of his army, and thus to increase his chances of grabbing the prize at stake.

These two lemmas allow to establish the main proposition of this paper as follows.

Proposition 1: Given the conflict technology $p(F)$ and the size of the warlord's group's population $N$, there exists a degree of the warlord's self interest:

$$
\widetilde{\theta}=\frac{1-f(1)}{2 \delta}
$$

such that $q=0$ is the global equilibrium if $\theta \leq \widetilde{\theta}$. Otherwise $q=1$, and the warlord is regarded as a thug.

Proof: Substituting from (15) into (14) and from (21) into (20) allows to write the warlord's welfare level in each equilibrium respectively as:

$$
V(0)=p(F(0))-F(0)+(1-\theta) N
$$

and:

$$
V(1)=p(F(1))+\frac{N-F(1)}{2}-\theta(1-\delta) N
$$

Now, taking a Taylor expansion of $p(F)$ about $F(0)$, and evaluating it at $F=F(1)$, while taking due account of the fact that $p^{\prime}(F(0))=1$, by definition, entails that:

$$
p(F(1))-p(F(0)) \cong F(1)-F(0) .
$$

It follows that the difference in the warlord's welfare levels between the two local optima may be written as: 
$V(0)-V(1) \cong \delta N\left(\frac{1-f(1)}{2 \delta}-\theta\right)$

Therefore, this difference is positive when $\theta \leq \widetilde{\theta}$, in which case the hero equilibrium is the global optimum. Otherwise, this difference is negative, making the thug equilibrium the global optimum. QED

Notice that the upper bound given in (25) is always below that given in (13) as $f(0)<f(1) \leq 1$. Hence, the two conditions for a hero equilibrium to exist and for it to be the global equilibrium are consistent. Similarly, the cutoff line given by (25) always lie above the lower bound given in (19), so that a thug equilibrium prevails whenever the global optimum is not the hero equilibrium.

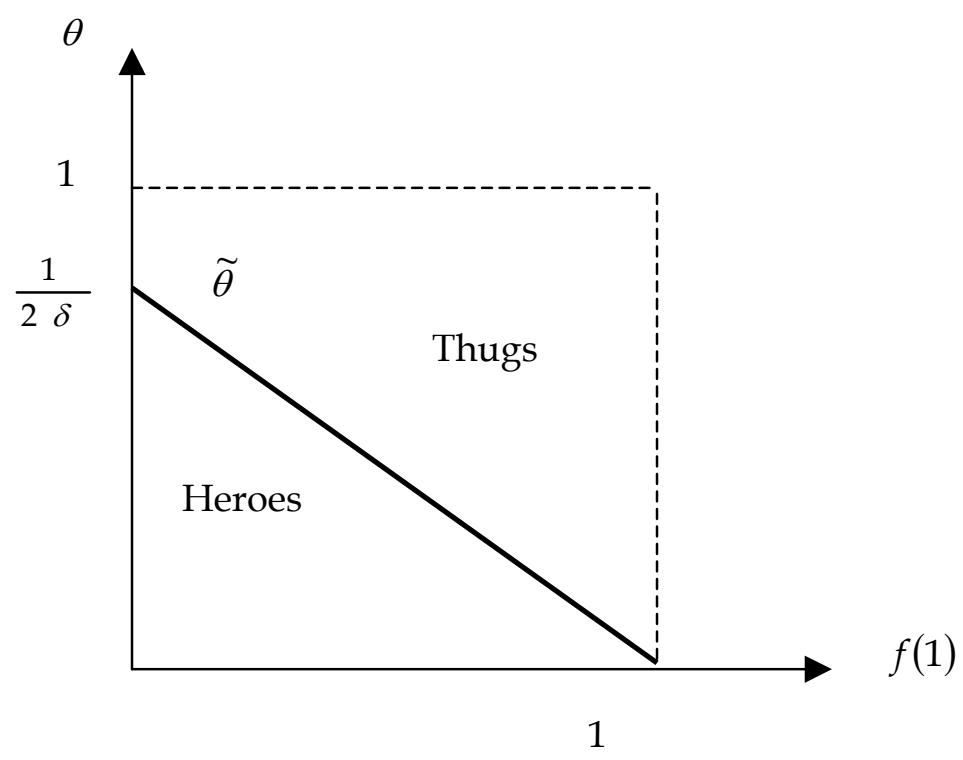

Figure 1: Sorting Out Thugs and Heroes

Figure 1 depicts this relationship, describing the borderline case (26) as the downward sloping straight line. Then, from (29), one finds that $q=1$ if the pair of parameters $\{\theta, f(0)\}$ is located above this cutoff line, and that $q=0$ below it. The case depicted at figure 1 assumes that $\delta>1 / 2$, but the opposite case is straightforward to depict as well. 
Proposition 1, and figure 1 which is derived from it, show that knowing the warlord's degree of self interest is not enough for predicting whether he will behave like a thug or like a hero. Knowledge of $f(1)$ is needed also. This is spelt out in corollary 1 below.

Corollary 1: The choice of a thuggish behavior depends both on the warlord's ethical characteristics, embodied in $\theta$, on the conflict technology, through the decisiveness factor $F(1)$, and on the group's population's size $N$.

Remember that the decisiveness factor $F(0)$ was defined above such that $p^{\prime}(F)=1$. It is clear that $F(1)$ also increases whenever the $p^{\prime}(F)$ function shifts out, in the relevant neighborhood, i.e. when the fighting forces engaged become more decisive. Hence the slight abuse of language used in corollary 1 , which is unlikely to be misleading. Then, $f(1)$ is also an increasing function of the decisiveness factor. Hence, one would expect an increased incidence of thuggish behavior as time passes, because the technology of conflict evolves over time, making arguably the forces engaged ever more decisive. The result is that insurgents have nowadays an incentive to engage a larger level of forces, and thus have a good reason to try and depress the wage rate further down.

Notice also that $f(1)$ depends as well negatively on the size of the relevant population, as mentioned above. The intuition is that the larger the group's population, the more expensive it is to hire raiders for having a given impact on the soldiers' wage. Hence, when comparing two warlords with the same degree of self interest, and having access to the same conflict technology, one would expect the guerilla leader from the smallest group to be more likely to behave like a thug, victimizing his own people, than the leader of a larger group. This seems to fit quite well with the observed behavior of Samuel Doe or Charles Taylor in Liberia, as well as that of Foday Sankoh in Sierra Leone (Reno, 1998). Another aspect of the intuition behind this result is that, faced with a large population, the warlord has an incentive to keep wages high, even if his degree of altruism is quite small, but not zero, as can be seen by looking at (6) and (8). A fall in the wage rate will then affect much less the utilitarian part of the warlord's objective function if the relevant population is small than 
when it is large. It is only in the limiting case of the perfect egoist $(\theta=0)$ that this consideration plays no part at all.

The simple model analyzed in the foregoing section does not take into account the possibility of an external intervention. However, nowadays in poor countries, the occurrence of civil war generally gives rise to some humanitarian intervention, either by the U.N. organizations, or by some NGOs. Refugee camps and relief operations are part and parcel with current civil wars. The next section offers an extension of the basic model that includes such a humanitarian intervention. This can be dealt with using only simple modifications of the previous model.

\section{The Impact of Relief Operations}

The model of the previous section has shown how the warlord's preferences and the parameters of the conflict technology combine to determine whether he will behave like a thug or like a hero, assuming that no external intervention will be forthcoming. However, ever since the Biaffra war, where "Médecins sans Frontières" (also known as the "French Doctors") started their operations, humanitarian interventions are almost always forthcoming whenever civilians get attacked by soldiers, or get victimized one way or another. The issue arises then whether this response provides more or less incentives to the warlords to victimize their people, because the welfare cost of the latter action is reduced. Then, one argument could be that relief operations might induce more thuggery, by shielding to some extent the warlord's conscience. Robbing the farmers could then be viewed as an indirect way of taxing the humanitarian actors, at a relatively small cost to the former. The present section aims at giving an answer to this query.

Assume now that there exists an idealized humanitarian actor, which is liable to provide some comfort to the affected civilians. More precisely, assume that whenever the raiders grab $\delta$ from a farmer, humanitarian aid is able to compensate partly the farmer by delivering some aid, given as a fixed amount $a \leq \delta$. The latter may also be interpreted as an expected value, if the humanitarian actor is only able to deliver the relief to the affected farmer with some probability less than 1 , may be for lack of information, or for other reasons. 
Then, this model predicts that such a relief system, which is admittedly pretty idealized, reduces the range of parameter values for which a thuggish behavior is adopted. This is the point made at proposition 2 below.

In order to establish the latter, we need a bit more notation. Define $F^{a}(0)<F(0)$ by $p^{\prime}\left(F^{a}(0)\right)=1+a$, and $f^{a}(0)=F^{a}(0) / N$, and define $F^{a}(1)<F(1)$ by $p^{\prime}\left(F^{a}(1)\right)=\frac{1+a}{2}$, with $f^{a}(1)=F^{a}(1) / N$. This allows to express proposition 2 as:

Proposition 2: Given the conflict technology $p(F)$ and the size of the warlord's group's population $N$, as well as the amount of aid per farmer $a$ given by the relief operation, there exists a degree of the warlord's self interest:

$$
\theta^{a}=\frac{1-f^{a}(1)+a\left(1+f^{a}(1)-2 f^{a}(0)\right)}{2(\delta-a)} \geq \tilde{\theta},
$$

such that $q=0$ if $\theta \leq \theta^{a}$, and $q=1$ above that point.

Proof: Define $\varepsilon=\delta-a$ as the effective damage inflicted to the farmer by the raiders, after taking due account of the compensation provided by the relief operation. Then the warlord's problem is to maximize the following expression:

$$
V=p(F)+(1+a) \frac{N-F}{1+q}-\theta(1-\varepsilon q) N
$$

Then, a hero equilibrium is a local optimum if:

$$
p^{\prime}(F)=1+a,
$$

and:

$$
\frac{\partial V(0)}{\partial q}=\varepsilon \theta N-(1+a)\left(N-F^{a}(0)\right)<0,
$$

which occurs if:

$$
\theta<\frac{(1+a)\left(1-f^{a}(0)\right)}{\delta-a} .
$$


Hence, the upper bound described by (34) is higher than that described in (13), showing that humanitarian relief expands the set of parameter values for which a hero equilibrium is a local optimum.

Similarly, a thug equilibrium is a local optimum if:

$$
p^{\prime}(F)=\frac{1+a}{2}
$$

and:

$$
\frac{\partial V(1)}{\partial q}=\varepsilon \theta N-(1+a) \frac{N-F^{a}(1)}{4} \geq 0
$$

The latter occurs if:

$$
\theta \geq \frac{(1+a)\left(1-f^{a}(1)\right)}{4(\delta-a)}
$$

Hence, the range of parameter values for which a thug equilibrium is a local optimum is reduced by the introduction of humanitarian relief.

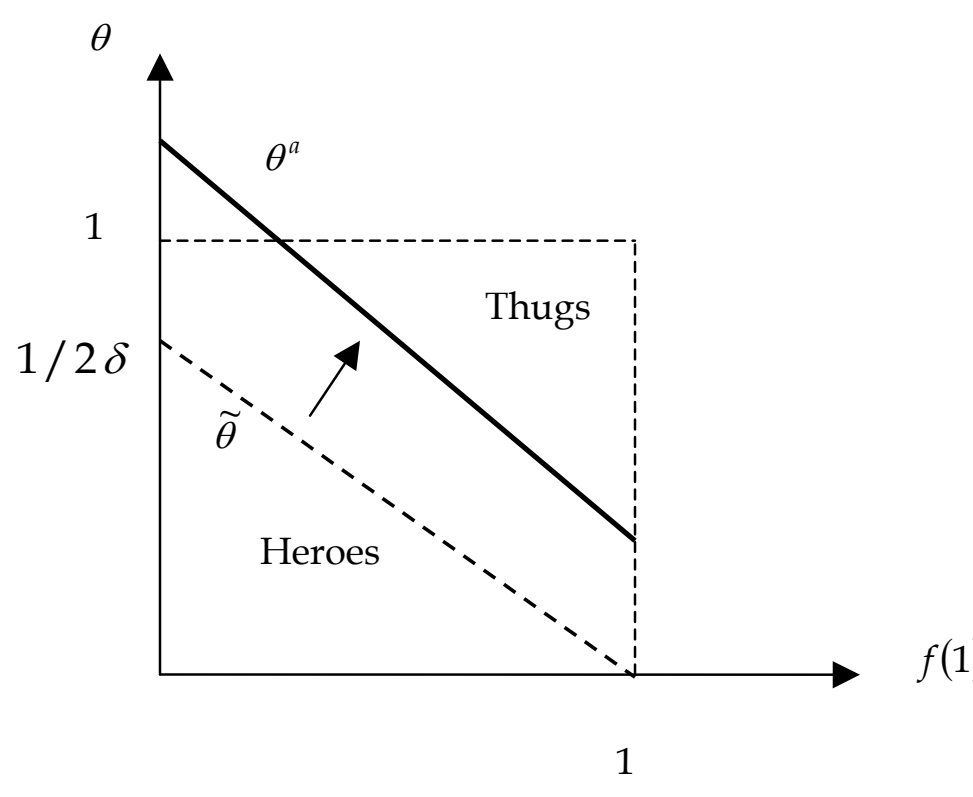

Figure 2: Impact of Relief on the Cut Off Line

Now, we can compare the warlord's welfare level in the two equilibria, using the same approach as in the previous section, to find: 


$$
V(0)-V(1) \cong N\left(\frac{(a-1) f^{a}(1)-2 a f^{a}(0)+1+a}{2}-\theta \varepsilon\right) .
$$

The latter is positive if $\theta \leq \theta^{a}$, defined by (30). Moreover, it is easily checked that $\theta^{a}$ lies below the upper bound for the existence of a hero equilibrium given in (34), being equal to it only in the limiting case where $f^{a}(1)=1$.

Then, it is easy to prove that $\theta^{a} \geq \widetilde{\theta}$, as $f^{a}(0)<f^{a}(1) \leq 1$. QED

The impact of humanitarian relief thus enlarges the set of parameter values for which a hero equilibrium is the global optimum, and consequently, makes the thuggish behavior less common. This is illustrated at figure 2.

Proposition 2 thus shows that humanitarian intervention, admittedly modeled here in a pretty idealized fashion, is providing relief by two channels. The first one is that the farmers get some compensation for the damage inflicted by the warlord's raiders. The second one is more indirect, and works through the warlord's incentives. Because of the reduced efficacy of the raids for depressing the market wage rate, the warlord is less inclined to pay soldiers for doing this job. Moreover, because the soldiers' reservation wage remains high, thanks to the limited effect of the raiding on the farmers' net incomes, it is more costly to the warlord to send the raiders to the farms. The result of this combination of higher wage cost and lower efficacy at depressing wages is that the range of values of the warlord's degree of self interest for which he chooses to behave like a thug shrinks. In other words, the borderline between the two types of behavior shifts upwards in the space of figure 1, as a response to the introduction of relief, as depicted at figure 2. This implies that the marginal thug will become a hero as humanitarian actors turn up. This effect may be called the "humanitarian contagion effect". This response of thuggery to the change in incentives entailed by the introduction of relief highlights the importance of the strategic dimension in the choice of inflicting violence on the civilians. The loot collected per raider is the same as in the previous section, but the incentive to raid the civilians is greatly reduced by the provision of relief. 
Moreover, this result provides an additional reason for giving up the value-laden words discussed above, as it brings out another determinant of thuggery that is unrelated to the warlord's ethical characteristics. This is spelt out in the following proposition, which shows that the set of parameter values for which thuggery is chosen might be made empty by the appropriate choice of $a$.

Proposition 3: The incidence of thuggery, as defined here as violence imposed by warlords against their own civilians, would disappear if a level of relief $a \geq a_{H}$ was provided by humanitarian intervention, where

$$
a_{H}=\frac{2 \delta-\left(1-f^{a}(1)\right)}{3+f^{a}(1)-2 f^{a}(0)}<\delta .
$$

Proof: The cut off value of the warlord's degree of self interest that triggers thuggery is easily shown to be an increasing function of $a$ :

$$
\frac{\partial \theta^{a}}{\partial a}=\frac{\delta\left(1+f^{a}(1)-2 f^{a}(0)\right)+1-f^{a}(1)}{2(\delta-a)^{2}}>0 .
$$

Hence, the $\theta^{a}$ line shifts upwards as $a$ increases. Then, there exists a level of relief such that the set of parameter values for which the thuggish behavior is chosen becomes empty. This can easily be computed by looking at the value of $a$ such that $\theta^{a}=1$, which is $a_{H}$ given by (40).

\section{Conclusion}

This paper has presented a partial equilibrium model for analyzing the reasons why some warlords inflict some violence on their own civilians. This is the criterion used here for labeling them as "thugs". This is an important phenomenon, which has been observed in several civil wars, and seems particularly puzzling to the outside observer. The simple framework analyzed here allows to provide some microeconomic foundations to such a behavior, and thus to identify some factors that are liable to make it emerge as the outcome 
of a rational choice made by a warlord. The importance of three factors has been highlighted: (i) the warlord's degree of self interest, (ii) the decisiveness factor of the conflict technology, and (iii) the population size of the group on behalf of which the warlord is waging the war. Hence, this model predicts that thugs would emerge in civil wars from small groups, using a highly decisive conflict technology, and would have a high degree of self interest. Hence, the increased presence of thugs in modern civil wars, which Mueller (2003) believes to have identified, could be due to a change in the technology of conflict as much as to some sort of moral decay. It could also be due to the disaggregation of ethnic or religious groups into smaller units, may be as a response to "modernization".

In this model, the warlord does not control perfectly his own folks, and can only attract individuals to join in his army if the incentives are right for doing so. The farmer will only accept to switch to soldiering if his earnings are the same in the two occupations. This participation constraint plays a crucial part in the model, as the warlord can use it strategically. By stepping up the raiding activity of his soldiers against the civilians from his own side, the warlord is not only able to collect more resources, but he is also able to reduce the soldiers' reservation wage. He is thus in a position to reduce his wage bill, and increase his profit. This in turn allows him to hire more soldiers, and thus to improve the odds for his victory. This creates increasing returns to raiding, in so far as increasing raiding reduces the cost of doing so, and thus provides an incentive to perform even more raiding. The resulting non-convexity of the warlord's objective function calls for a specific approach for analyzing this problem, quite different from the standard marginal analysis. However, the warlord will not necessarily wish to order this raiding, because of the negative impact on the people's welfare that this entails. Unless his degree of self interest is exceedingly high, the warlord might be deterred by this fact. The model is thus focusing on this trade off, and brings out the parameters that affect the warlord's choice.

This framework was easily extended to tackle the issue of the impact of humanitarian relief on the warlord's propensity to behave like a thug. Relief is modeled here as a partial insurance, whereby the farmer gets some compensation whenever he is raided by the soldiers from his side. In this model, this reduces the warlord's incentive to raid the farmers, 
because it reduces the effectiveness of the farmers' participation constraint as a lever for depressing the soldiers' wage cost. This dampens clearly the strategic motive for raiding farmers, with a view to reduce wage costs, and only leaves the pure looting aspect, or revenue raising motive. This impact of introducing relief into the model is thus a nice way to highlight the strategic role played by looting in this model, beside the "taxation" of some resources for funding the war effort.

The model rests on some simplifying assumptions, that a deeper analysis should aim at making richer and more realistic. First, it uses a partial equilibrium framework, while a general equilibrium setting might be desirable, in order to bring out the possible interactions between the two contending armies. In particular, looting by one side might reduce the ability of the other side to collect revenues from the same farmers, so that some preemptive raiding might be performed strategically for starving the other side of resources. Second, the soldiers are pretty ruthless in this model, while one might assume that raiding their own side might deteriorate their morale, and reduce their fighting efficiency. Third, the farmers might in fact adopt various self-protective measures, like hiding their crop from the raiders. Azam et al. (1994) provide some evidence that farmers had hidden quite a lot of coffee during the first phase of the Angolan war, and then flooded the market with it in 1986-88, when a cease fire occurred and macroeconomic balance was restored. The farmers could also organize some self-defense groups, as has been observed recently during the Algerian civil war. Moreover, the risk of being raided might have some impact on the supply side, as farmers might flee to more remote areas, where the soldiers find it harder to catch them, or might switch to different crops, returning for example to low-quality subsistence crops, which are less valuable for looting.

Fourth, the assumptions made about relief are pretty rough, and provide an idealized picture of the latter as an insurance scheme. In the real world, farmers usually have to join refugee camps for getting some humanitarian support, and thus have to give up farming, or at least to neglect it somewhat. This raises some tricky issues, which have been neglected in the literature. Very often, farmers are in fact moving back and forth between the refugee camp and their own farm, in order to salvage whatever can be salvaged from their crop, and 
look after their remaining belongings. However, this possibility is closed when the camps are located too far away. On the other hand, if the camps are located close enough to the border, they can be used as a base camp by the guerilla. This has been observed during the war in Congo (Olsson and Congdon Fors, 2004). The international community is now conscious of the ambiguous role of refugee camps during civil wars (Gauer, 2003). For example, the HCR has interfered with the movement of refugees across the border between Guinea and Liberia or Sierra Leone, and has displaced its refugee camps. The aim of this controversial move was to cut off the Liberian and Sierra Leonian guerillas from the resources provided by the refugee camps, which they were racketeering. However, the displaced camps were then deserted by the refugees, raising doubts about the strategic role of refugee camps in some civil wars. One may thus wonder whether they actually provide an incentive for warlords to terrorize peasants away, with a view to attract humanitarian aid, that can in turn be racketeered away for feeding the guerilla. Africa Watch (1991) illustrates how the Ethiopian army, under the Derg regime, diverted the humanitarian aid supplies, including food aid, during the 1984 famine, against the background of the civil war. It used it for feeding its own army, and did not let any supplies reach the affected areas, located in the enemy's region of origin. Sealing off some areas with a view to starve off its population, as was done for example against Biaffra during the Nigeria civil war, may also be regarded as a form of violence against civilians.

This sample of remaining issues suggests that violence against civilians should attract more attention from conflict scientists. Many puzzles remain, and their solution seems urgent, for mitigating the plight of the civilians victims of civil wars, whose life does not weigh much in most of the third world. 


\section{References}

Abdullah, Ibrahim, and Patrick Muana (1998): “The Revolutionary United Front of Sierra Leone", in Christopher Clapham (Ed.): African Guerillas, 172-193, James Currey: Oxford.

Africa Watch (1991): Evil Days. 30 Years of War and Famine in Ethiopia (written by Alex de Waal), Human Rights Watch: New York.

Azam, Jean-Paul (1992): “The Agricultural Minimum Wage and Wheat Production in Morocco (1971-89)", Journal of African Economies, 1 (2), 171-191.

Azam, Jean-Paul (2002): “Looting and Conflict between Ethno-Regional Groups: Lessons for State Formation in Africa", Journal of Conflict Resolution, 46 (1), 131-153.

Azam, Jean-Paul and Anke Hoeffler (2002): "Violence against Civilians in Civil Wars: Looting or Terror?", Journal of Peace Research, 39 (4), 461-485.

Azam, Jean-Paul and Alice Mesnard (2003): "Civil War and the Social Contract", Public Choice, 115 (3-4), 455-475.

Azam, Jean-Paul, Paul Collier and Andrea Cravinho (1994): “Crop Sales, Shortages and Peasant Portfolio Behaviour: an Analysis of Angola", Journal of Development Studies, 30 (2), 361-379.

Benouaret, Lynda (2004): La guerre civile en Algérie (1992-2002): un enjeu économique ou religieux?, unpublished DEA dissertation, ARQADE: Toulouse.

Cairns, Edmund (1997): A Safer Future: Reducing the Human Cost of War, Oxford: Oxfam Publications .

Collier, Paul (2000): "Rebellion as a Quasi-Criminal Activity", Journal of Conflict Resolution, 44 (6), 839-853.

Collier, Paul and Anke Hoeffler (forthcoming): "Greed and Grievance in Civil War", Oxford Economic Papers.

Gauer, Denys (2003): "Liberian and Sierra Leonian Refugees in Guinea", paper presented at the "Conflict and Development Policy in the Mano River Region and Côte d'Ivoire" Conference, 13-14 May 2003: Paris. 
Gay, Peter (1966): The Enlightenment. The Rise of Modern Paganism, Norton: New York.

Grossman, Herschel I. (1991): “A General Equilibrium Model of Insurrection”, American Economic Review, 81 (4), 912-921.

Herbst, Jeff (2000): “Economic Incentives, Natural Resources and Conflict in Africa', Journal of African Economies, 9 (3), 270-94.

Hirshleifer, Jack (1991): “The Paradox of Power", Economics and Politics, 3, 177-200.

Hirschleifer Jack (1995): “Anarchy and its Breakdown”, Journal of Political Economy, 103 (1), $26-52$.

Hobsbaum, Eric (2000): Bandits, London: Abacus.

Lévy, Bernard-Henri (2001): Réflexion sur la Guerre, le Mal et la fin de l'Histoire, Grasset: Paris.

Little, Ian M. D. (2002): Ethics, Economics \& Politics. Principles of Public Policy, Oxford University Press: Oxford.

Mueller, John (2003): “Policing the Remnants of War", Journal of Peace Research, 40 (5), 507518.

Mutibwa, Phares (1992): Uganda since Independence. A Story of Unfulfilled Hopes, Hurst \& Company: London.

Olsson, Ola, and Heather Congdon Fors (2004): "Congo: the Prize of Predation", Journal of Peace Research , 41 (3), 321-336.

Pool, David (1998): “The Eritrean People's Liberation Front”, in Christopher Clapham (Ed.): African Guerillas, 19-35, James Currey: Oxford.

Reno, William (1998): Warlord Politics and African States, Lynne Rienner: Boulder and London.

Young, John (1998): “The Tigray People's Liberation Front”, in Christopher Clapham (Ed.): African Guerillas, 36-52, James Currey: Oxford.

World Bank (2003): Breaking the Conflict Trap. Civil War and Development Policy, Oxford University Press: New York. 